\title{
Evaluation of total intravenous anesthesia with propofol-guaifenesin-medetomidine and alfaxalone-guaifenesin-medetomidine in Thoroughbred horses undergoing castration
}

\author{
Motoki AOKI ${ }^{1)}$, Ai WAKUNO ${ }^{1) *}$, Asuka KUSHIRO'), Naomi MAE ${ }^{1)}$, \\ Masashi KAKIZAKI ${ }^{1)}$, Shun-ichi NAGATA ${ }^{2)}$ and Minoru OHTA ${ }^{1)}$ \\ ${ }^{1)}$ Racehorse Clinic, Miho Training Center, Japan Racing Association, Ibaraki 300-0493, Japan \\ 2)Laboratory of Racing Chemistry, Tochigi 320-0851, Japan
}

J. Vet. Med. Sci.

79(12): 2011-2018, 2017

doi: 10.1292/jvms.16-0658

Received: 5 January 2017

Accepted: 1 October 2017

Published online in J-STAGE:

23 October 2017
ABSTRACT. Anesthetic and cardiorespiratory effects of total intravenous anesthesia (TIVA) technique using propofol-guaifenesin-medetomidine (PGM) and alfaxalone-guaifenesinmedetomidine (AGM) were preliminarily evaluated in Thoroughbred horses undergoing castration. Twelve male Thoroughbred horses were assigned randomly into two groups. After premedication with intravenous (IV) administrations of medetomidine $(5.0 \mu \mathrm{g} / \mathrm{kg})$ and butorphanol $(0.02 \mathrm{mg} / \mathrm{kg})$, anesthesia was induced with guaifenesin $(10 \mathrm{mg} / \mathrm{kg} \mathrm{IV})$, followed by either propofol (2.0 mg/kg IV) (group PGM: $n=6$ ) or alfaxalone ( $1.0 \mathrm{mg} / \mathrm{kg}$ IV) (group AGM: $n=6$ ). Surgical anesthesia was maintained for $60 \mathrm{~min}$ at a constant infusion of either propofol $(3.0 \mathrm{mg} /$ $\mathrm{kg} / \mathrm{hr}$ ) (group PGM) or alfaxalone (1.5 mg/kg/hr) (group AGM), in combination with guaifenesin $(80 \mathrm{mg} / \mathrm{kg} / \mathrm{hr}$ ) and medetomidine $(3.0 \mu \mathrm{g} / \mathrm{kg} / \mathrm{hr})$. Responses to surgical stimuli, cardiorespiratory values, and induction and recovery characteristics were recorded throughout anesthesia. During anesthesia induction, one horse paddled in group PGM. All horses from group AGM were maintained at adequate anesthetic depth for castration. In group PGM, 3 horses showed increased cremaster muscle tension and one showed slight movement requiring additional IV propofol to maintain surgical anesthesia. No horse exhibited apnea, although arterial oxygen tension decreased in group AGM to less than $60 \mathrm{mmHg}$. Recovery quality was good to excellent in both groups. In conclusion, TIVA using PGM and AGM infusion was available for 60 min anesthesia in Thoroughbred horses. TIVA techniques using PGM and AGM infusion provided clinically acceptable general anesthesia with mild cardiorespiratory depression. However, inspired air should be supplemented with oxygen to prevent hypoxemia during anesthesia.

KEY WORDS: alfaxalone, horse, propofol, TIVA

In horses, surgical procedures requiring anesthesia for more than $30 \mathrm{~min}$ can be realized with simultaneous infusions of ketamine, $\alpha_{2}$-adrenoceptor agonists ( $\alpha_{2}$-agonists), and centrally acting muscle relaxants. The combination of guaifenesin, ketamine and xylazine ("Triple drip") has been popularized since 1986 [2, 15, 35, 47]. In current equine practice, Triple drip is one of the most commonly used total intravenous anesthesia (TIVA) techniques under field conditions. This technique and its modifications using different $\alpha_{2}$-agonists or water-soluble benzodiazepines can be safely administered for 90 min in horses [24, 25].

Ketamine is a dissociative anesthetic that has been used for induction of anesthesia and TIVA in horses for a long time [15]. However, ketamine may become unavailable in many countries due to its international scheduling in near future. Therefore, it is an urgent problem to develop a TIVA regimen that does not involve the use of ketamine. It is expected that propofol and alfaxalone may overcome this concern because of their pharmacokinetic properties in horses [14, 38].

Propofol (2, 6-diisopropylphenol) is an injectable anesthetic agent that acts on the gamma aminobutyric acid $\mathrm{GABA}_{\mathrm{A}}$ receptors in the central nervous system. It is a popular intravenous (IV) anesthetic used in humans, dogs and cats, and its anesthetic effect is characterized by a smooth and rapid onset and short duration of action [23, 43]. Furthermore, propofol is suitable for TIVA in horses because it does not produce active metabolites and exhibits minimal accumulation when administered for infusion over

*Correspondence to: Wakuno, A.: Ai_Wakuno@jra.go.jp

O2017 The Japanese Society of Veterinary Science

This is an open-access article distributed under the terms of the Creative Commons Attribution Non-Commercial No Derivatives (by-nc-nd) License. (CC-BY-NC-ND 4.0: https://creativecommons.org/licenses/by-nc-nd/4.0/) 
$60 \mathrm{~min}$ in ponies [38]. However, it was reported that unpredictable behavioral responses, including paddling or myotonus in the front half of the body, can be frequently observed during the induction of anesthesia with propofol in horses [3, 5, 26, 27, 40]. In addition, an infusion of propofol alone is inappropriate for maintenance of anesthesia because of its poor analgesic properties and tendency to cause respiratory depression in horses [30,37]. Therefore, propofol is used as a maintenance agent in combination with analgesics, such as $\alpha_{2}$-agonists, opioids, ketamine and lidocaine, but exclusively in research settings [3-5, 11, 19, 28, 30, 37, 41].

Medetomidine has high selectivity for $\alpha_{2}$-adrenergic receptors and produces potent $\alpha_{2}$-adrenergic effects, including muscle relaxation, central nervous system depression and analgesia in horses $[7,8,16,44]$. TIVA techniques using a combination of propofol and medetomidine have been reported to produce clinically adequate anesthetic conditions for surgical procedures $[4,39]$. However, Oku et al. [39] reported that a brief period of apnea was observed in 3 out of 6 horses castrated under propofolmedetomidine TIVA. Moreover, Bettschart-Wolfensberger et al. [4] reported that 23 of 50 horses anesthetized with propofolmedetomidine TIVA required positive pressure ventilation to overcome hypoventilation. As such, propofol-induced respiratory depression during maintenance of anesthesia remains an important clinical concern if mechanical ventilation is not available, such as in conditions of field anesthesia.

Guaifenesin is a centrally acting muscle relaxant that is widely used in equine anesthesia as a constituent of Triple drip as mentioned above. Guaifenesin prevents unpredictable adverse behavioral responses, for example paddling, during the anesthetic induction with propofol [6]. The respiratory depression produced during the propofol-medetomidine TIVA may be reduced by co-administration of guaifenesin, which indicates a possibility of decreasing the infusion dose of propofol required for maintaining surgical anesthesia. Therefore, it is worthwhile to investigate TIVA technique using a combination of propofol, guaifenesin and medetomidine in horses.

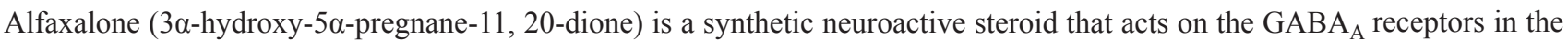
central nervous system, resulting in loss of consciousness and muscle relaxation. Alfaxalone has similar clinical characteristics to propofol $[1,10]$ and has been used for induction of anesthesia in many animal species [17, 20, 29, 32, 33]. In horses, alfaxalone showed similar anesthetic induction and recovery effects and cardiorespiratory responses to ketamine and thiopental [45]. In addition, alfaxalone has desirable pharmacokinetic characteristics for TIVA, and is rapidly eliminated from the plasma in horses $[13,22]$. Therefore, alfaxalone may be a possible alternative to ketamine that constitutes Triple drip and its modifications. It is worthwhile to investigate TIVA technique using a combination of alfaxalone, guaifenesin and medetomidine in horses. In addition, no published data regarding changes in plasma alfaxalone concentration in horses that received alfaxalone infusion are currently available.

The present study was designed to preliminary evaluate anesthetics and cardiorespiratory effects of TIVA techniques using an infusion of propofol-guaifenesin-medetomidine (PGM-TIVA) or alfaxalone-guaifenesin-medetomidine (AGM-TIVA) in horses. Time course changes in plasma concentrations of alfaxalone were also measured during and after AGM infusion. We hypothesized that both PGM-TIVA and AGM-TIVA techniques might provide appropriate surgical anesthesia for castration in Thoroughbred horses.

\section{MATERIALS AND METHODS}

\section{Horses}

Twelve male race-retired Thoroughbred horses scheduled for surgical castration were assigned randomly into two groups (PGM group: $\mathrm{n}=6$; AGM group: $\mathrm{n}=6$ ). The median age and body weights were 3.6 years (range: $3.2-4.3$ years) and $468 \mathrm{~kg}$ (range: 420-520 kg) in group PGM, and 3.3 years (range: $2.1-3.4$ years) and $454 \mathrm{~kg}$ (range: $420-480 \mathrm{~kg}$ ) in group AGM, respectively. No abnormality was detected on the general physical examination, the pre-anesthetic blood examination and electrocardiography in any horse. Food, but not water, was withheld for $12 \mathrm{hr}$ prior to anesthesia. All horses were treated with intramuscular (IM) administration of penicillin (8,000 IU/kg: Mycillin Inj NZ, Nippon Zenyaku Kogyo Co., Ltd., Fukushima, Japan) and flunixin meglumine (1 mg/kg IV: Banamine injection-5\%, DS Pharma Animal Health Co., Ltd., Osaka, Japan) before surgery. This study was performed according to the Guidelines for Animal Experiments at the Equine Research Institute, Japan Racing Association.

\section{Anesthesia and surgical protocol}

A 14-gauge, 60-mm catheter was placed in the left external jugular vein in both groups for drug administration, and a second catheter was placed in the right external jugular vein for collection of venous blood samples in group AGM. The horses were premedicated with medetomidine (5.0 $\mu \mathrm{g} / \mathrm{kg}$ IV: Domitor, Orion Corp., Espoo, Finland) and butorphanol (0.02 mg/kg IV: Vetorphale, Meiji Seika Co., Ltd., Tokyo, Japan). Ten min after premedication, anesthesia was induced with guaifenesin (10 mg/kg IV: $5 \%$ Guaifenesin, Shinyo Pure Chemicals Co., Ltd., Osaka, Japan) followed immediately by either propofol (2.0 mg/kg IV: $1 \%$ Propofol, Nichi-Iko Pharmaceutical Co., Ltd., Toyama, Japan) (group PGM) or alfaxalone (1.0 mg/kg IV: Alfaxan, Jurox Pty Ltd., NSW, Australia) (group AGM).

Horses were then positioned in left lateral recumbency on a padded surgical mat. Thereafter, surgical anesthesia was maintained for $60 \mathrm{~min}$ with constant rate infusion (CRI) of either propofol (3.0 mg/kg/hr) (group PGM) or alfaxalone (1.5 mg/kg/hr) (group AGM), in combination with guaifenesin $(80 \mathrm{mg} / \mathrm{kg} / \mathrm{hr}$ CRI) and medetomidine $(3.0 \mu \mathrm{g} / \mathrm{kg} / \mathrm{hr}$ CRI). Propofol or alfaxalone, guaifenesin and medetomidine were mixed together in one bottle and administered using an infusion pump (IVAC 599, Cardinal Health 303 Inc., San Diego, CA, U.S.A.) via the primary line. Horses were allowed to spontaneously breathe atmospheric air throughout anesthesia. The surgeons administered a $400 \mathrm{mg}$ of lidocaine (2\% Xylocaine, AstraZeneca Co., Ltd., Osaka, Japan) into 
each testicle 10 min before the start of surgery.

The syringes and fluid lines were covered by the black tapes, so that the surgeons were blinded to anesthetic drug combination that the horses received. A junior surgeon performed the castration using a semi-closed surgical technique under the supervision of an experienced surgeon. The same surgeons performed procedures throughout the study. In order to equalize the operation time, surgeries were performed between 15-45 min after the start of the PGM or AGM infusion. Surgical conditions (the cremaster muscle tension and movement against surgical stimuli) were assessed by the surgeons, and an additional IV dose of either propofol $(0.5 \mathrm{mg} / \mathrm{kg}$ ) (group PGM) or alfaxalone $(0.25 \mathrm{mg} / \mathrm{kg}$ ) (group AGM) was administered if the surgeon judged the level of anesthesia to be inadequate for surgery. Horses were allowed to recover unassisted and received no additional drugs.

\section{Anesthetic monitoring}

The time from the end of anesthetic drug administration to the time when horses became lateral recumbent (induction time) was recorded. The quality of induction was subjectively assessed by 2 experienced anesthetists who were blinded to anesthetic drug combination using a scoring scale of 1-5 (1: poor, 2: marginal, 3: fair, 4: good, 5: excellent), as previously described [27].

Heart rate (HR) and respiratory rate (RR) were recorded by auscultation and visually before premedication (baseline) and every 10 min after starting the CRI of anesthetic drug combination. A 20-gauge, 51-mm catheter was placed in the facial or transverse facial artery, and systolic arterial blood pressure (SAP), mean arterial blood pressure (MAP), and diastolic arterial blood pressure (DAP) were monitored using a multipurpose monitoring system (BSM-2301, Nihon Kohden Co., Ltd., Tokyo, Japan) every 10 min. The electrocardiogram was continuously monitored using a standard base-apex lead configuration immediately after the induction of anesthesia. Arterial blood samples were collected at the same time of cardiovascular monitoring and arterial oxygen tension $\left(\mathrm{PaO}_{2}\right)$, arterial carbon dioxide tension $\left(\mathrm{PaCO}_{2}\right)$, and arterial blood $\mathrm{pH}$ were immediately analyzed using a blood gas analyzer (ABL800 FLEX, Radiometer Co., Ltd., Tokyo, Japan). The typical signs of anesthetic depth (eye position, nystagmus, palpebral reflex and muscle tone) were continuously monitored.

The time from the end of PGM or AGM infusion to the first movement, sternal recumbency, the first attempt to stand and standing (recovery time) were recorded. The quality of recovery was assessed by anesthetists who were blinded to the anesthetic drug combination using the same scoring scale [27].

\section{Plasma alfaxalone analysis}

Blood samples of $10 \mathrm{~m} l$ were collected from the right external jugular catheter at 15, 30, 45 and 60 min of anesthesia and immediately after standing in group AGM. All blood samples were immediately placed on ice, and the plasma was separated from blood and frozen at $-20^{\circ} \mathrm{C}$.

Alfaxalone was recovered from plasma samples by liquid-liquid extraction using methyl tert-butyl ether, with 11-hydroxy progesterone as the internal standard. The extracted substance was analyzed using liquid chromatography-tandem mass spectrometry (LC-MS/MS) by electrospray ionization in positive ion mode. LC-MS/MS system consisted of Shimadzu prominence HPLC system (Shimadzu Co., Tokyo, Japan) and AB Sciex QTRAP 4000 mass spectrometer (AB Sciex, Framingham, MA, U.S.A.). The calibration was performed using linear standard curves in the range of $10-500 \mathrm{mg} / \mathrm{l}$, and the coefficient of correlation $\left(\mathrm{r}^{2}\right)$ exceeded 0.995 . The lower limit of quantification was $10 \mathrm{ng} / \mathrm{ml}$, and the recovery and repeatability were 94.0 and $4.8 \%$, respectively. Analysis of data was performed using SAAM-II program (University of Washington, Seattle, WA, U.S.A.).

\section{Statistical analysis}

All results were expressed as medians (range). Statistical analysis of data was carried out using JMP 8 (SAS Institute Japan Ltd., Tokyo, Japan). Cardiorespiratory data were analyzed using Friedman's test. The Mann-Whitney $U$ test (between the groups) and Steel test (between baseline and each subsequent measurement point within group) were used when significant differences were observed. Induction and recovery data between the groups were compared using the Mann-Whitney $U$ test, and the level of statistical significance was set at $P<0.05$.

\section{RESULTS}

Induction quality scores and induction times are shown in Table 1. No significant differences in induction quality score were observed between the groups. All horses from group AGM and 5 of 6 horses from group PGM scored 4 (good) or higher. One horse in group PGM scored 1 (poor) because the horse excited with severe muscular tremors and rigidity during transition to lateral recumbency and paddled its front and hindlimbs for approximately one min after attaining lateral recumbency. The time from the end of induction drug administration to lateral recumbency was similar in both groups.

Intermittent nystagmus or blinking was observed throughout anesthesia in both groups. Surgeons judged that anesthesia level of all horses from group AGM was adequately maintained for castration, and no additional IV administration of alfaxalone was required. In group PGM, surgeons commented on increased cremaster muscle tension in 3 out of 6 horses, and slight ear and/or limbs movement was observed in one of these horses in response to surgical stimulation. This horse exhibited gross purposeful movement with hypertension ( $\mathrm{SAP}>200 \mathrm{mmHg}$ ) at $20 \mathrm{~min}$ and an additional dose of propofol $(0.5 \mathrm{mg} / \mathrm{kg} \mathrm{IV}) \mathrm{was}$ administered to achieve a sufficient level of anesthesia for surgery.

The time course changes in cardiorespiratory variables are shown in Table 2. No significant differences in HR were observed between the groups at any time points. No cardiac arrhythmia was detected throughout anesthesia. No significant differences in 
Table 1. Induction and recovery quality scores and times of total intravenous anesthesia using propofolguaifenesin-medetomidine (Group PGM) and alfaxalone-guaifenesin-medetomidine (Group AGM)

\begin{tabular}{lccc}
\hline & Group PGM & Group AGM & $P$ value \\
\hline $\begin{array}{l}\text { Induction quality score } \\
\text { Time from the end of anesthetic induction drug administration }\end{array}$ & $4(1-5)$ & $5(4-5)$ & 0.13 \\
$\quad$ & $46(40-65)$ & $49(41-61)$ & 0.48 \\
$\quad$ to lateral recumbency (sec) & $4(3-5)$ & $5(3-5)$ & 0.54 \\
Recovery quality score & & & \\
Time from the end of constant rate infusion & $22(12-42)$ & $32(29-40)$ & 0.31 \\
$\quad$ to the first movement (min) & $31(17-55)$ & $51(43-79)$ & 0.09 \\
$\quad$ to sternal recumbency (min) & $37(31-64)$ & $56(45-79)$ & 0.06 \\
to the first attempt to stand (min) & $43(32-64)$ & $56(45-79)$ & 0.08 \\
$\quad$ to standing (min) & & &
\end{tabular}

Data are expressed as median (range).

Table 2. Heart rate (HR), systolic arterial blood pressure (SAP), mean arterial blood pressure (MAP), diastolic arterial blood pressure (DAP), respiratory rate $(\mathrm{RR})$, arterial oxygen tension $(\mathrm{PaO} 2)$, arterial carbon dioxide tension $(\mathrm{PaCO} 2)$ and blood $\mathrm{pH}$ in horses anesthetized with total intravenous anesthesia technique using propofol-guaifenesin-medetomidine (Group PGM: $n=6$ ) and alfaxalone-guaifenesin-medetomidine (Group AGM: $\mathrm{n}=6$ ) before premedication (baseline) and at every 10 min of anesthesia

\begin{tabular}{|c|c|c|c|c|c|c|c|}
\hline & Baseline & $10 \mathrm{~min}$ & $20 \mathrm{~min}$ & $30 \mathrm{~min}$ & $40 \mathrm{~min}$ & $50 \mathrm{~min}$ & $60 \mathrm{~min}$ \\
\hline \multicolumn{8}{|l|}{ HR (beats/min) } \\
\hline Group PGM & $36(30-48)$ & $22(20-28)^{\mathrm{a}}$ & $24(20-43)$ & $23(20-46)$ & $23(20-44)$ & $23(20-42)$ & $24(25-33)^{\mathrm{a}}$ \\
\hline Group AGM & $36(30-36)$ & $25(24-30)^{\mathrm{a}}$ & $26(24-30)^{\mathrm{a}}$ & $27(25-31)^{\mathrm{a}}$ & $27(23-32)^{\mathrm{a}}$ & $28(24-34)$ & $28(25-33)^{\mathrm{a}}$ \\
\hline \multicolumn{8}{|l|}{ SAP (mmHg) } \\
\hline Group PGM & $\mathrm{n} / \mathrm{a}$ & $129(118-170)$ & $123(107-223)$ & $123(110-185)$ & $123(107-154)$ & $123(107-150)$ & $115(103-130)$ \\
\hline Group AGM & $\mathrm{n} / \mathrm{a}$ & $150(130-162)$ & $140(125-162)$ & $139(125-159)$ & $141(123-157)$ & $138(123-152)$ & $134(116-149)$ \\
\hline \multicolumn{8}{|l|}{ MAP (mmHg) } \\
\hline Group PGM & $\mathrm{n} / \mathrm{a}$ & $103(84-130)$ & $97(90-164)$ & $98(91-142)$ & $98(86-133)$ & $95(85-122)$ & $89(83-111)$ \\
\hline Group AGM & $\mathrm{n} / \mathrm{a}$ & $117(108-135)$ & $113(100-136)$ & $110(95-133)$ & $111(89-131)$ & $109(90-128)$ & $105(92-125)$ \\
\hline \multicolumn{8}{|l|}{ DAP $(\mathrm{mmHg})$} \\
\hline Group PGM & $\mathrm{n} / \mathrm{a}$ & $87(70-110)$ & $82(77-142)$ & $83(81-127)$ & $81(75-119)$ & $80(67-107)$ & $74(70-98)$ \\
\hline Group AGM & $\mathrm{n} / \mathrm{a}$ & $100(92-120)$ & $100(83-121)$ & $97(80-117)$ & $97(72-115)$ & $95(73-111)$ & $92(75-107)$ \\
\hline \multicolumn{8}{|l|}{ RR (breaths/min) } \\
\hline Group PGM & $15(12-18)$ & $9(7-12)^{\mathrm{a}}$ & $10(6-12)^{\mathrm{a}}$ & $10(5-12)^{\mathrm{a}}$ & $9(5-12)^{\mathrm{a}}$ & $9(5-16)$ & $9(5-12)^{\mathrm{a}}$ \\
\hline Group AGM & $12(12-15)$ & $5(3-10)^{\mathrm{a}, \mathrm{b}}$ & $5(3-9)^{\mathrm{a}, \mathrm{b}}$ & $5(3-9)^{\mathrm{a}, \mathrm{b}}$ & $5(4-8)^{\mathrm{a}, \mathrm{b}}$ & $5(4-8)^{\mathrm{a}, \mathrm{b}}$ & $5(4-9)^{\mathrm{a}, \mathrm{b}}$ \\
\hline \multicolumn{8}{|l|}{$\mathrm{PaO}_{2}(\mathrm{mmHg})$} \\
\hline Group PGM & $\mathrm{n} / \mathrm{a}$ & $66.6(61.8-67.9)$ & $64.2(59.1-66.4)$ & $63.1(58.4-69.0)$ & $60.8(57.8-65.9)$ & $63.8(60.5-70.7)$ & $61.4(57.8-67.0)$ \\
\hline Group AGM & $\mathrm{n} / \mathrm{a}$ & $55.5(40.9-57.4)^{b}$ & $55.4(41.0-58.8)^{\mathrm{b}}$ & $54.5(36.0-55.8)^{\mathrm{b}}$ & $54.6(38.0-57.4)^{\mathrm{b}}$ & $54.9(38.1-60.0)^{\mathrm{b}}$ & $54.1(39.8-59.1)^{b}$ \\
\hline \multicolumn{8}{|l|}{$\mathrm{PaCO}_{2}(\mathrm{mmHg})$} \\
\hline Group PGM & $\mathrm{n} / \mathrm{a}$ & $50.8(46.6-57.0)$ & $51.6(48.2-57.2)$ & $51.3(47.5-57.8)$ & $52.7(49.0-59.0)$ & $53.5(48.1-58.6)$ & $53.9(49.2-60.9)$ \\
\hline Group AGM & $\mathrm{n} / \mathrm{a}$ & $50.8(49.1-53.4)$ & $51.2(49.1-54.5)$ & $52.4(50.6-55.6)$ & $54.1(50.4-55.9)$ & $55.1(51.6-60.0)$ & $55.9(51.4-59.2)$ \\
\hline \multicolumn{8}{|l|}{$\mathrm{pH}$} \\
\hline Group PGM & $\mathrm{n} / \mathrm{a}$ & $7.38(7.37-7.39)$ & $7.38(7.37-7.38)$ & $7.38(7.36-7.40)$ & 7.38 (7.35-7.39) & $7.38(7.35-7.39)$ & $7.38(7.35-7.38)$ \\
\hline Group AGM & $\mathrm{n} / \mathrm{a}$ & $7.38(7.37-7.39)$ & $7.38(7.36-7.40)$ & $7.38(7.35-7.39)$ & $7.37(7.36-7.38)$ & $7.37(7.34-7.38)$ & $7.36(7.34-7.39)$ \\
\hline
\end{tabular}

Data are expressed as median (range). n/a: not available. a) Significantly different from baseline values within the groups $(P<0.05)$. b) Significantly different between two groups $(P<0.05)$.

SAP, MAP or DAP, either between the groups or between any time points, were detected, although one horse showed hypertension at $20 \mathrm{~min}$ in response to surgical stimuli as mentioned above.

During anesthesia, horses from group PGM showed relatively shallow and Cheyne-stokes breathing, while the horses in group AGM exhibited relatively deep, slow and stable breathing patterns. When compared to baseline values, RR in group PGM was significantly reduced at all time points except at $50 \mathrm{~min}$. The RR in group AGM was significantly lower than baseline values at all time points and significantly lower than that in group PGM. However, no horse of either group exhibited apnea for more than one min. $\mathrm{PaO}_{2}, \mathrm{PaCO}_{2}$ and $\mathrm{pH}$ did not change significantly over time in either group. No significant differences were observed in $\mathrm{PaCO}_{2}$ and $\mathrm{pH}$ between the groups, while $\mathrm{PaO}_{2}$ values in group AGM were significantly lower than those in group PGM throughout anesthesia. Hypoxemia $\left(\mathrm{PaO}_{2}<60 \mathrm{mmHg}\right)$ was evident in 2 out of 6 horses in group PGM and in all 6 horses from group AGM.

Recovery quality scores and recovery times are also shown in Table 1 . Recoveries were uneventful in all cases, and no significant differences were observed in recovery quality score between the groups. No significant differences were detected in the time from the end of PGM or AGM infusion to the first movement, sternal recumbency, the first attempt to stand and standing. 


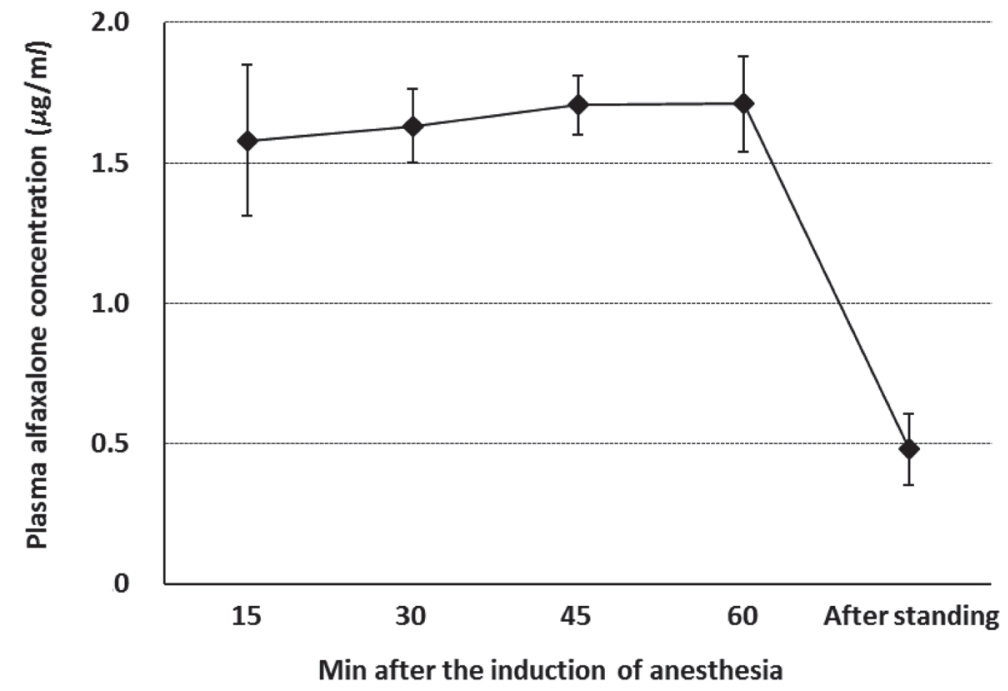

Fig. 1. Changes in plasma alfaxalone concentration $(\mu \mathrm{g} / \mathrm{m} l)$ during anesthesia and after standing in horses anesthetized with total intravenous anesthesia using infusions of alfaxalone, guaifenesin and medetomidine ( $\mathrm{n}=6)$. Blood samples were collected at 15, 30, 45 and $60 \mathrm{~min}$ of anesthesia and immediately after standing. Plots are mean values and error bars are standard deviations from 6 horses.

Changes in plasma alfaxalone concentration during anesthesia and after standing in group AGM are shown in Fig. 1. Mean plasma alfaxalone concentration was stable throughout anesthesia $(1.58-1.71 \mu \mathrm{g} / \mathrm{m} l)$ and decreased rapidly after anesthesia $(0.48 \mu \mathrm{g} / \mathrm{m} l)$.

\section{DISCUSSION}

In ponies, the administration of propofol after premedication with $\alpha_{2}$-agonists (xylazine or detomidine) has been reported to produce smooth induction with good muscle relaxation [36, 37]. In contrast, in the study of adult horses that received propofol $(2.0 \mathrm{mg} / \mathrm{kg} \mathrm{IV})$ after premedication with detomidine $(15 \mu \mathrm{g} / \mathrm{kg} \mathrm{IV})$, two out of 12 horses showed signs of excitement and one of them exhibited paddling activity after recumbency [30]. Ohta et al. [41] reported that Thoroughbred race horses that received propofol $(3.0 \mathrm{mg} / \mathrm{kg}$ IV) after premedication with xylazine $(1.0 \mathrm{mg} / \mathrm{kg} \mathrm{IV})$ and midazolam $(50 \mu \mathrm{g} / \mathrm{kg} \mathrm{IV})$ also showed similar results. These excitatory behaviors were unpredictable as all horses appeared to be well sedated before induction. Conversely, it has been reported that guaifenesin (73 $\pm 18 \mathrm{mg} / \mathrm{kg} \mathrm{IV})$ [6] or $(90 \mathrm{mg} / \mathrm{kg}$ IV) [28] prevented adverse anesthetic induction events caused by propofol. In the present study, guaifenesin $(10 \mathrm{mg} / \mathrm{kg} \mathrm{IV})$ was combined with propofol, and one horse from group PGM was excited with severe muscular tremors and rigidity during transition to lateral recumbency and paddled its front and hindlimbs for approximately one min after attaining lateral recumbency. This was possibly due to the fact that guaifenesin dose used in the present study was very small compared to that in previous studies $[6,28]$. In the present study, a low dose of guaifenesin combined with medetomidine and butorphanol was adopted considering the situation of field anesthesia and the need to avoid cumbersome equipment. However, there are still some concerns regarding quality during induction with propofol.

Wakuno et al. [45] reported that 2 out of 6 Thoroughbred horses that received IV alfaxalone after premedication with medetomidine $(5.0 \mu \mathrm{g} / \mathrm{kg} \mathrm{IV})$ and midazolam $(0.02 \mathrm{mg} / \mathrm{kg} \mathrm{IV})$ showed slight muscular rigidity or limb movement during transition to lateral recumbency. Keates et al. [21] reported that anesthesia induction with alfaxalone (1.0 $\mathrm{mg} / \mathrm{kg}$ IV) following premedication with xylazine $(0.5 \mathrm{mg} / \mathrm{kg} \mathrm{IV})$ and guaifenesin $(35 \mathrm{mg} / \mathrm{kg} \mathrm{IV})$ resulted in limb rigidity in 5 out of 6 horses. Conversely, it has been reported that induction with alfaxalone $(1.0 \mathrm{mg} / \mathrm{kg} \mathrm{IV})$ following premedication with acepromazine $(0.03 \mathrm{mg} / \mathrm{kg} \mathrm{IV})$, medetomidine $(7.0 \mu \mathrm{g} / \mathrm{kg} \mathrm{IV})$ and guaifenesin $(35 \mathrm{mg} / \mathrm{kg}$ IV) provided smooth transition to lateral recumbency and favorable conditions for tracheal intubation in horses [13]. In the present study, anesthesia induction was smooth in all horses anesthetized with alfaxalone $(1.0 \mathrm{mg} / \mathrm{kg} \mathrm{IV})$ following the premedication with medetomidine $(5.0 \mu \mathrm{g} / \mathrm{kg} \mathrm{IV})$, butorphanol $(0.02 \mathrm{mg} / \mathrm{kg}$ IV) and guaifenesin $(10 \mathrm{mg} / \mathrm{kg} \mathrm{IV})$, even though the dose of guaifenesin was small compared to that used in previous studies $(35 \mathrm{mg} / \mathrm{kg})$ [13, 21]. Therefore, it is expected that the combination of low dose guaifenesin, medetomidine and butorphanol may improve the induction quality of alfaxalone.

The infusion rates of AGM in the present study were determined on the basis of our preliminary experimental studies (unpublished data) and a previous report [13]. Goodwin et al. [13] reported that alfaxalone (2.0 mg/kg/hr CRI) and medetomidine $(5.0 \mu \mathrm{g} / \mathrm{kg} / \mathrm{hr} \mathrm{CRI})$ provided an adequate level of surgical anesthesia for castration and no additional doses or increases in infusion rates were required. In the present study, the infusion rate of alfaxalone required to maintain surgical anesthesia for castration in horses was effectively reduced by $25 \%$ compared to that reported by Goodwin et al. [13], using infusions of guaifenesin and medetomidine. 
The infusion rates of PGM in the present study were selected on the basis of previous reports [4, 15, 39]. BettschartWolfensberger et al. [4] reported that supplemental ketamine was required in 17 horses, and 14 of these horses required additional thiopental to maintain surgical anesthesia among 50 clinical horses in which anesthesia was maintained with propofol (5.9-6.5 mg/ $\mathrm{kg} / \mathrm{hr} \mathrm{CRI}$ ) and medetomidine (3.5 $\mu \mathrm{g} / \mathrm{kg} / \mathrm{hr}$ CRI) for elective surgery. Oku et al. [39] reported that propofol (6.0 mg/kg/hr CRI) and medetomidine $(3.0 \mu \mathrm{g} / \mathrm{kg} / \mathrm{hr}$ CRI) provided an adequate level of surgical anesthesia for castration in 4 out of 7 horses, while additional IV administration of propofol or thiopental was required in the remaining 3 horses. From these results, $6.0 \mathrm{mg} / \mathrm{kg} /$ $\mathrm{hr}$ of propofol was considered to be the minimum infusion rate required to achieve surgical levels of anesthesia when combined with medetomidine (3.0-3.5 $\mu \mathrm{g} / \mathrm{kg} / \mathrm{hr}$ CRI). Therefore, the infusion rate of propofol was set at $3.0 \mathrm{mg} / \mathrm{kg} / \mathrm{hr}$ with the expectation that the addition of guaifenesin would reduce propofol requirement. However, the TIVA technique with PGM infusion resulted in movements in response to surgical stimuli in 3 out of 6 horses. Therefore, this propofol infusion rate $(3.0 \mathrm{mg} / \mathrm{kg} / \mathrm{hr} \mathrm{CRI}) \mathrm{seemed}$ to be insufficient to achieve the surgical depth of anesthesia for castration in horses anesthetized with the PGM-TIVA technique. Because the infusions of guaifenesin and medetomidine might produce $25 \%$ reduction in alfaxalone requirement as mentioned above, it was supposed that $4.5 \mathrm{mg} / \mathrm{kg} / \mathrm{hr}$ of propofol infusion rate might provide an adequate anesthetic effect for castration in horses under PGM-TIVA.

In the present study, HR and arterial blood pressures were stable throughout anesthesia in both groups. Although HR values were significantly lower during anesthesia than baseline values, they remained within commonly acceptable limits for horses under general anesthesia. Generally, a MAP $>70 \mathrm{mmHg}$ is considered necessary for prevention of postoperative myopathy. While blood pressure was slightly elevated in horses anesthetized with PGM-TIVA and AGM-TIVA, MAPs were maintained at comparable value as with other similar TIVA techniques [13, 39]. Yamashita et al. [46] reported that an IV injection of medetomidine induced increases in peripheral vascular resistance in horses. Therefore, it was considered that the increases in peripheral vascular resistance due to medetomidine might contribute to the high blood pressure. Although the evaluation of cardiovascular function was limited to $\mathrm{HR}$ and blood pressure in the present study, it appeared that cardiovascular functions were maintained within an acceptable level during anesthesia in horses anesthetized with PGM-TIVA and AGM-TIVA.

Both propofol and alfaxalone are known to cause apnea when used in high doses in dogs [32, 34]. During PGM-TIVA or AGM-TIVA, spontaneous respiration was maintained in all horses, although mild hypercapnia $\left(\mathrm{PaCO}_{2}=55-60 \mathrm{mmHg}\right)$ developed. The horses anesthetized with PGM-TIVA showed relatively shallow and Cheyne-stokes breathing with significantly higher RR, while the horses anesthetized with AGM-TIVA exhibited relatively deep, slow and stable breathing patterns with significantly lower RR. Although these breathing patterns varied between individual horses, these differences in respiration seemed to reflect the insufficient depth of anesthesia in horses anesthetized with PGM-TIVA as mentioned above. While the tidal volume was not measured in the present study, it was suggested that the minute ventilation might be maintained at acceptable levels during PGMTIVA and AGM-TIVA, because the horses developed only mild hypercapnia. In contrast, $\mathrm{PaO}_{2}$ values during anesthesia were remarkably lower than the expected values in horses that were awake and breathing air. Ventilation perfusion mismatch resulting from recumbent postures were likely to cause severe hypoxemia, which is a common problem in field anesthesia [9]. Alfaxalone induction in horses premedicated with xylazine and guaifenesin caused hypoxemia $\left(\mathrm{PaO}_{2}<55 \mathrm{mmHg}\right)$ because of ventilation perfusion mismatching rather than respiratory depression due to the drugs administered [21]. Although the $\mathrm{P}_{(\mathrm{A}-\mathrm{a})} \mathrm{O}_{2}$ values were not measured in the present study, it was considered that comparable factors induced hypoxemia in horses anesthetized with PGMTIVA and AGM-TIVA. Nasotracheal oxygen insufflation might help improving $\mathrm{PaO}_{2}$ values, but it is necessary to examine the details in cardiorespiratory function in horses anesthetized with PGM-TIVA and AGM-TIVA.

It was reported that the majority of horses anesthetized with alfaxalone $3.0 \mathrm{mg} / \mathrm{kg} / \mathrm{hr}$ CRI for $3 \mathrm{hr}$ showed excitement and hyperesthesia shortly after the cessation of alfaxalone infusion [12]. These undesirable behaviors were not observed in horses anesthetized with AGM-TIVA, and this was possibly due to the fact that the total infusion dose of alfaxalone was much lower in these horses than those used in a previous report [12]. On the other hand, Goodwin et al. [13] reported that the horses anesthetized with infusions of alfaxalone $(2.0 \mathrm{mg} / \mathrm{kg} / \mathrm{hr} \mathrm{CRI})$ and medetomidine $(5.0 \mu \mathrm{g} / \mathrm{kg} / \mathrm{hr} \mathrm{CRI})$ for $45 \mathrm{~min}$ stood on their first attempt and their recoveries were judged good to excellent. However, total anesthesia time was much shorter in the present study compared to the previous report [13]. In the present study, recoveries were uneventful and smooth in all horses. Median recovery times were also considered appropriate for the duration of anesthesia. Sedation with an $\alpha_{2}$-agonist during the recovery period prevents early movement and improves the quality of recovery in horses [18, 31, 42]. Although plasma medetomidine concentration was not measured in the present study, it was considered that a residual sedative effect of medetomidine after the cessation of its CRI might prevent excitation during recovery period.

The mean plasma concentration of alfaxalone during surgery ranged from approximately 1.6 to $1.7 \mu \mathrm{g} / \mathrm{m} l$ and rapidly decreased after the cessation of alfaxalone infusion. The mean plasma concentration of alfaxalone was approximately $0.5 \mu \mathrm{g} / \mathrm{m} l \mathrm{in}$ standing horses (median, $56 \mathrm{~min}$; range, 45-79 $\mathrm{min}$ ). The eliminating half-time was roughly estimated at approximately $40 \mathrm{~min}$; this value was close to the elimination half-time following a $1.0 \mathrm{mg} / \mathrm{kg}$ of bolus IV alfaxalone (33.4 min) in horses [14]. It was reconfirmed that alfaxalone has a suitable pharmacokinetic effect when used with TIVA in horses.

In conclusion, TIVA techniques using PGM and AGM infusions provided clinically acceptable general anesthesia with mild cardiorespiratory depression in horses. These TIVA techniques may be useful for a moderate period (60 min) of anesthesia, although propofol infusion rate should be reexamined. However, inspired air should be supplemented with oxygen to prevent hypoxemia during anesthesia. 


\section{REFERENCES}

1. Ambros, B., Duke-Novakovski, T. and Pasloske, K. S. 2008. Comparison of the anesthetic efficacy and cardiopulmonary effects of continuous rate infusions of alfaxalone-2-hydroxypropyl-beta-cyclodextrin and propofol in dogs. Am. J. Vet. Res. 69: 1391-1398. [Medline] [CrossRef]

2. Baetge, C. L., Matthews, N. S. and Carroll, G. L. 2007. Comparison of 3 total intravenous anesthetic infusion combinations in adult horses. Int. J. Appl. Res. Vet. Med. 5: 1-8.

3. Bettschart-Wolfensberger, R., Freeman, S. L., Jäggin-Schmucker, N. and Clarke, K. W. 2001. Infusion of a combination of propofol and medetomidine for long-term anesthesia in ponies. Am. J. Vet. Res. 62: 500-507. [Medline] [CrossRef]

4. Bettschart-Wolfensberger, R., Kalchofner, K., Neges, K., Kästner, S. and Fürst, A. 2005. Total intravenous anaesthesia in horses using medetomidine and propofol. Vet. Anaesth. Analg. 32: 348-354. [Medline] [CrossRef]

5. Bettschart-Wolfensberger, R., Bowen, M. I., Freeman, S. L., Feller, R., Bettschart, R. W., Nolan, A. and Clarke, K. W. 2001. Cardiopulmonary effects of prolonged anesthesia via propofol-medetomidine infusion in ponies. Am. J. Vet. Res. 62: 1428-1435. [Medline] [CrossRef]

6. Brosnan, R. J., Steffey, E. P., Escobar, A., Palazoglu, M. and Fiehn, O. 2011. Anesthetic induction with guaifenesin and propofol in adult horses. Am. J. Vet. Res. 72: 1569-1575. [Medline] [CrossRef]

7. Bryant, C. E., England, G. C. and Clarke, K. W. 1991. Comparison of the sedative effects of medetomidine and xylazine in horses. Vet. Rec. 129: 421-423. [Medline] [CrossRef]

8. Bueno, A. C., Cornick-Seahorn, J., Seahorn, T. L., Hosgood, G. and Moore, R. M. 1999. Cardiopulmonary and sedative effects of intravenous administration of low doses of medetomidine and xylazine to adult horses. Am. J. Vet. Res. 60: 1371-1376. [Medline]

9. Coutu, P., Caulkett, N., Pang, D. and Boysen, S. 2015. Efficacy of a portable oxygen concentrator with pulsed delivery for treatment of hypoxemia during equine field anesthesia. Vet. Anaesth. Analg. 42: 518-526. [Medline] [CrossRef]

10. Ferré, P. J., Pasloske, K., Whittem, T., Ranasinghe, M. G., Li, Q. and Lefebvre, H. P. 2006. Plasma pharmacokinetics of alfaxalone in dogs after an intravenous bolus of Alfaxan-CD RTU. Vet. Anaesth. Analg. 33: 229-236. [Medline] [CrossRef]

11. Flaherty, D., Reid, J., Welsh, E., Monteiro, A. M., Lerche, P. and Nolan, A. 1997. A pharmacodynamic study of propofol or propofol and ketamine infusions in ponies undergoing surgery. Res. Vet. Sci. 62: 179-184. [Medline] [CrossRef]

12. Goodwin, W. A., Keates, H. L. and Pasloske, K. 2009. Total intravenous anaesthesia (TIVA) in the horse with alfaxalone (abstract). p. 87. In: Proceedings of the 10th World Congress of Veterinary Anaesthesiology, Glasgow.

13. Goodwin, W. A., Keates, H. L., Pearson, M. and Pasloske, K. 2013. Alfaxalone and medetomidine intravenous infusion to maintain anaesthesia in colts undergoing field castration. Equine Vet. J. 45: 315-319. [Medline] [CrossRef]

14. Goodwin, W. A., Keates, H. L., Pasloske, K., Pearson, M., Sauer, B. and Ranasinghe, M. G. 2011. The pharmacokinetics and pharmacodynamics of the injectable anaesthetic alfaxalone in the horse. Vet. Anaesth. Analg. 38: 431-438. [Medline] [CrossRef]

15. Greene, S. A., Thurmon, J. C., Tranquilli, W. J. and Benson, G. J. 1986. Cardiopulmonary effects of continuous intravenous infusion of guaifenesin, ketamine, and xylazine in ponies. Am. J. Vet. Res. 47: 2364-2367. [Medline]

16. Grimsrud, K. N., Mama, K. R., Steffey, E. P. and Stanley, S. D. 2012. Pharmacokinetics and pharmacodynamics of intravenous medetomidine in the horse. Vet. Anaesth. Analg. 39: 38-48. [Medline] [CrossRef]

17. Grint, N. J., Smith, H. E. and Senior, J. M. 2008. Clinical evaluation of alfaxalone in cyclodextrin for the induction of anaesthesia in rabbits. Vet. Rec. 163: 395-396. [Medline] [CrossRef]

18. Ida, K. K., Fantoni, D. T., Ibiapina, B. T., Souto, M. T., Zoppa, A. L., Silva, L. C. and Ambrósio, A. M. 2013. Effect of postoperative xylazine administration on cardiopulmonary function and recovery quality after isoflurane anesthesia in horses. Vet. Surg. 42: 877-884. [Medline]

19. Ishizuka, T., Itami, T., Tamura, J., Saitoh, Y., Saitoh, M., Umar, M. A., Miyoshi, K., Yamashita, K. and Muir, W. W. 2013. Anesthetic and cardiorespiratory effects of propofol, medetomidine, lidocaine and butorphanol total intravenous anesthesia in horses. J. Vet. Med. Sci. 75: $165-172$. [Medline] [CrossRef]

20. Keates, H. 2003. Induction of anaesthesia in pigs using a new alphaxalone formulation. Vet. Rec. 153: 627-628. [Medline] [CrossRef]

21. Keates, H. L., van Eps, A. W. and Pearson, M. R. 2012. Alfaxalone compared with ketamine for induction of anaesthesia in horses following xylazine and guaifenesin. Vet. Anaesth. Analg. 39: 591-598. [Medline] [CrossRef]

22. Klöppel, H. and Leece, E. A. 2011. Comparison of ketamine and alfaxalone for induction and maintenance of anaesthesia in ponies undergoing castration. Vet. Anaesth. Analg. 38: 37-43. [Medline] [CrossRef]

23. Langley, M. S. and Heel, R. C. 1988. Propofol. A review of its pharmacodynamic and pharmacokinetic properties and use as an intravenous anaesthetic. Drugs 35: 334-372. [Medline] [CrossRef]

24. Lerche, P. 2013. Total intravenous anesthesia in horses. Vet. Clin. North Am. Equine Pract. 29: 123-129. [Medline] [CrossRef]

25. Luna, S. P., Taylor, P. M. and Bloomfield, M. 1997. Endocrine changes in cerebrospinal fluid, pituitary effluent, and peripheral plasma of anesthetized ponies. Am. J. Vet. Res. 58: 765-770. [Medline]

26. Mama, K. R., Steffey, E. P. and Pascoe, P. J. 1995. Evaluation of propofol as a general anesthetic for horses. Vet. Surg. 24: 188-194. [Medline] [CrossRef]

27. Mama, K. R., Steffey, E. P. and Pascoe, P. J. 1996. Evaluation of propofol for general anesthesia in premedicated horses. Am. J. Vet. Res. 57: 512-516. [Medline]

28. Mama, K. R., Pascoe, P. J., Steffey, E. P. and Kollias-Baker, C. 1998. Comparison of two techniques for total intravenous anesthesia in horses. Am. J. Vet. Res. 59: 1292-1298. [Medline]

29. Maney, J. K., Shepard, M. K., Braun, C., Cremer, J. and Hofmeister, E. H. 2013. A comparison of cardiopulmonary and anesthetic effects of an induction dose of alfaxalone or propofol in dogs. Vet. Anaesth. Analg. 40: 237-244. [Medline] [CrossRef]

30. Matthews, N. S., Hartsfield, S. M., Hague, B., Carroll, G. L. and Short, C. E. 1999. Detomidine-propofol anesthesia for abdominal surgery in horses. Vet. Surg. 28: 196-201. [Medline] [CrossRef]

31. Matthews, N. S., Hartsfield, S. M., Mercer, D., Beleau, M. H. and MacKenthun, A. 1998. Recovery from sevoflurane anesthesia in horses: comparison to isoflurane and effect of postmedication with xylazine. Vet. Surg. 27: 480-485. [Medline] [CrossRef]

32. Muir, W., Lerche, P., Wiese, A., Nelson, L., Pasloske, K. and Whittem, T. 2008. Cardiorespiratory and anesthetic effects of clinical and supraclinical doses of alfaxalone in dogs. Vet. Anaesth. Analg. 35: 451-462. [Medline] [CrossRef]

33. Muir, W., Lerche, P., Wiese, A., Nelson, L., Pasloske, K. and Whittem, T. 2009. The cardiorespiratory and anesthetic effects of clinical and supraclinical doses of alfaxalone in cats. Vet. Anaesth. Analg. 36: 42-54. [Medline] [CrossRef]

34. Muir, W. W. 3rd. and Gadawski, J. E. 1998. Respiratory depression and apnea induced by propofol in dogs. Am. J. Vet. Res. 59: 157-161. [Medline]

35. Muir, W. W., Skarda, R. T. and Sheehan, W. 1978. Evaluation of xylazine, guaifenesin, and ketamine hydrochloride for restraint in horses. Am. J. Vet. Res. 39: 1274-1278. [Medline] 
36. Nolan, A. M. and Chambers, J. P. 1989. The use of propofol as an induction agent after detomidine premedication in ponies. J. Assoc. Vet. Anaeth. 16: $30-32$.

37. Nolan, A. M. and Hall, L. W. 1985. Total intravenous anaesthesia in the horse with propofol. Equine Vet. J. 17: 394-398. [Medline] [CrossRef]

38. Nolan, A., Reid, J., Welsh, E., Flaherty, D., McCormack, R. and Monteiro, A. M. 1996. Simultaneous infusions of propofol and ketamine in ponies premedicated with detomidine: a pharmacokinetic study. Res. Vet. Sci. 60: 262-266. [Medline] [CrossRef]

39. Oku, K., Kakizaki, M., Ono, K. and Ohta, M. 2011. Clinical evaluation of total intravenous anesthesia using a combination of propofol and medetomidine following anesthesia induction with medetomidine, guaifenesin and propofol for castration in Thoroughbred horses. J. Vet. Med. Sci. 73: 1639-1643. [Medline] [CrossRef]

40. Oku, K., Yamanaka, T., Ashihara, N., Kawasaki, K., Mizuno, Y. and Fujinaga, T. 2003. Clinical observations during induction and recovery of xylazine-midazolam- propofol anesthesia in horses. J. Vet. Med. Sci. 65: 805-808. [Medline] [CrossRef]

41. Ohta, M., Oku, K., Mukai, K., Akiyama, K. and Mizuno, Y. 2004. Propofol-ketamine anesthesia for internal fixation of fractures in racehorses. $J$. Vet. Med. Sci. 66: 1433-1436. [Medline] [CrossRef]

42. Santos, M., Fuente, M., Garcia-Iturralde, R., Herran, R., Lopez-Sanroman, J. and Tendillo, F. J. 2003. Effects of alpha-2 adrenoceptor agonists during recovery from isoflurane anaesthesia in horses. Equine Vet. J. 35: 170-175. [Medline] [CrossRef]

43. Sebel, P. S. and Lowdon, J. D. 1989. Propofol: a new intravenous anesthetic. Anesthesiology 71: 260-277. [Medline] [CrossRef]

44. Valverde, A. 2010. Alpha-2 agonists as pain therapy in horses. Vet. Clin. North Am. Equine Pract. 26: 515-532. [Medline] [CrossRef]

45. Wakuno, A., Aoki, M., Kushiro, A., Mae, N., Kodaira, K., Maeda, T., Yamazaki, Y. and Ohta, M. 2017. Comparison of alfaxalone, ketamine and thiopental for anaesthetic induction and recovery in Thoroughbred horses premedicated with medetomidine and midazolam. Equine Vet. J. 49: 94-98. [Medline] [CrossRef]

46. Yamashita, K., Tsubakishita, S., Futaok, S., Ueda, I., Hamaguchi, H., Seno, T., Katoh, S., Izumisawa, Y., Kotani, T. and Muir, W. W. 2000. Cardiovascular effects of medetomidine, detomidine and xylazine in horses. J. Vet. Med. Sci. 62: 1025-1032. [Medline] [CrossRef]

47. Young, L. E., Bartram, D. H., Diamond, M. J., Gregg, A. S. and Jones, R. S. 1993. Clinical evaluation of an infusion of xylazine, guaifenesin and ketamine for maintenance of anaesthesia in horses. Equine Vet. J. 25: 115-119. [Medline] [CrossRef] 